A. Fuentes, G. Legros, P. Joulain, J.P. Vantelon and J.L. Torero, Evaluation of the Extinction Factor in a Laminar Flame Established over a PMMA Plate in Microgravity, Microgravity Sci. Technol. 17 (2005) 10-14.

\title{
Evaluation of the Extinction Factor in a Laminar Flame Established over a PMMA Plate in Microgravity
}

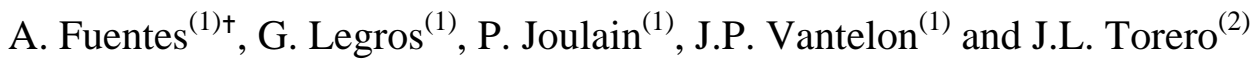 \\ (1) Laboratoire de Combustion et de Détonique, UPR 9028 du CNRS - Poitiers, FRANCE \\ (2) School of Engineering and Electronics, The University of Edinburgh, Edinburgh, UNITED KINGDOM \\ † Corresponding author
}

\begin{abstract}
A methodology for estimating the extinction factor at $\lambda=530 \mathrm{~nm}$ in diffusion flames is presented. All experiments have been in microgravity and have as their objective the production of quantitative data that can serve to evaluate the soot volume fraction. A better understanding of soot formation and radiative heat transfer is of extreme importance to many practical combustion related processes such as spacecraft fire safety. The experimental methodology implements non-axisymmetric configurations that provide a laminar diffusion flame at atmospheric pressure. PMMA is used as fuel. The oxidizer flows parallel to its surface. Optical measurements are performed at the $4.74 \mathrm{~s}$ ZARM drop tower.
\end{abstract}

\section{Introduction}

Reduction of buoyancy in flames affects the dominant mechanisms driving heat transfer, burning rates and the flame shape. Due to the absence of natural convection, time scales associated with combustion processes are much longer and radiation can be the predominant mode of heat transfer even for small diffusion flames [1]. Soot production is also enhanced with increasing residence times, further emphasizing the role of radiation [2]. Thus, a better understanding of soot formation and radiative emissions for microgravity diffusion flames is of extreme importance to many practical combustion related processes such as spacecraft fire safety ([1, 3, 4]). In addition, non- 
buoyant flames burning in microgravity offer themselves as an attractive platform to gain a better understanding of soot mechanisms in practical systems [5].

Soot concentrations are the result of two competitive processes, soot production and oxidation. Both processes are influenced by the oxygen concentration, therefore local soot concentrations depend on the structure of the flow field in the proximity of the flame. Smoke point studies conducted with axisymetric jet flames showed that this dependency can be modified by the experimental set-up [6, 7] or the global residence time [2, 8, 9]. Konsur et al. [8] highlighted that the peak soot volume fraction decreased when reducing the characteristic flow residence time and Mortazavi et al. [10] demonstrated the capability to alter soot characteristic residence times in non-buoyant laminar jet diffusion flames by varying characteristic velocities. Using a boundary layer geometry, Vietoris et al. [11] and Brahmi et al. [12] further showed that the luminosity of a diffusion flame established in microgravity increased with the oxidizer velocity. A subsequent numerical study proved that the orientation of the flow streamlines was at the origin of these changes in luminous intensity [13]. Since luminous intensity can be correlated to soot oxidation, these observations provide indirect evidence of the importance of the flow field on the outcome of the soot production/oxidation competition. Furthermore, they imply that global residence times are not sufficient and that soot measurements cannot be directly extrapolated between different configurations.

The objective of this work is to better understand soot formation in boundary layer, non-buoyant diffusion flames and quantify soot concentrations for the purpose of obtaining more adequate radiation calculations. For this purpose this paper provides detailed measurements of extinction factors in micro-gravity on the flat plate PMMA burner used in previous experiments by Vietoris et al. [11]. Extinction measurement is a technique that is widely used in the combustion community. It is an attractive technique because it provides an instantaneous, nonintrusive measurement of the soot volume fraction. Furthermore, the current work aims at expanding this optical technique for characterizing soot volume fraction in non-bouyant flames using a solid fuel. 


\section{Experimental hardware}

The diffusion flame is established inside a 50 liter stainless steel combustion chamber. Confinement is required for safety in microgravity facilities but all perturbations linked to confinement have been studied before, showing that the volume of the chamber is sufficient to keep the flame free from boundary effects.

Figure 1 represents a schematic of the combustion chamber. The pressure is kept at atmospheric values by means of a pressure differential switch connected between the chamber and the proportional valve placed at the exhaust of the duct. Exhaust gases are stored in the vacuum tank during the drop. The PMMA solid fuel is placed inside the combustion chamber on the plate. The oxidizer flow is introduced through the chamber by means of five openings and then it passes through a filter and honeycomb plates to guarantee a laminar flow. Mass flow is controlled by BROOKS 5830E driven from an acquisition and command board. The oxidizer used corresponds to a mixture of $35 \% \mathrm{O}_{2}$ and $65 \% \mathrm{~N}_{2}$. The combustion chamber has three large quartz windows for optical access.

Backlighting is carried out by means of eight Luxeon green LEDs, each power light source has a Lambertien emitting radiation pattern i.e., the relativity intensity of each diode is centered in relation to spatial radiation. Emitted rays possess a wavelength of $\lambda=530 \mathrm{~nm}$ and crossed first three frosted glass windows to guarantee the scattering of light intensity and then crossed the flame in the $y$ direction where they were partially absorbed, the schematic of experimental set-up is show in Fig. 2. The zone of interest was immediately above the burner in the luminous region containing soot particles, thus the backlighting was centered at this location so that the light beams can be considered parallel and coming straight to mirror. The beams were directed through a $540 \mathrm{~nm}$ filter with a $50 \mathrm{~nm}$ bandwidth.

In order to get a two-dimensional view of the reaction, a Sony monochrome digital camera is placed just above the mirror. The camera features an interline transfer CCD with progressive scan readout and allows a frame rate of $25 \mathrm{fps}$ in high resolution. 
During each experimental run, the LEDs are synchronized with the video output signal coming from the camera. The schematic of this procedure is show in Fig. 3. The dotted lines indicate reference frames obtained from backlighting but with no flame. Thus, frames with no flame were taken before ignition of a flame, and were used for obtaining reference intensities. With the flame the same synchronization procedure is used, i.e. four frames when the LEDs are on and four frames when they are off.

As shown in Fig. 3, there are two types of images captured when the LEDs are on - 1) intensity of the LEDs while there is no flame, and 2) intensity transmitted when flames are present and two types of images captured when the LEDs are off - 3) the background intensity and 4) the light from the flame.

Microgravity conditions were obtained at the ZARM Drop Tower. This installation delivers $4.74 \mathrm{~s}$ with gravity level about of $10^{-6} g_{0}$. Further details on the experimental procedures can be found in reference [14].

\section{Extinction measurement}

Extinction measurements can be performed to determine the behavior of the quenching zone in the flame and to map the soot volume fractions $f_{\text {soot }}(x, z)$, if the soot distribution is two-dimensional, i.e. that $\frac{\partial f_{\text {soot }}}{\partial y}<<\frac{\partial f_{\text {soot }}}{\partial z}$ and $\frac{\partial f_{\text {soot }}}{\partial y}<<\frac{\partial f_{\text {soot }}}{\partial z}$.

According to Bouguer's law, under the assumption that extinction is composed of absorption and scattering, the extent of the light intensity $i$ extinction along a path 0 to Ly and parallel to the $y$ axis (cf Fig. 2), is given by the following ratio:

$$
\frac{i_{\lambda}(x, L y, z)}{i_{\lambda}(x, 0, z)}=e^{-\int_{0}^{L y} k_{\lambda}(x, y, z) d y}
$$


where $k_{\lambda}(x, y, z)$ is the local extinction coefficient. It can be demonstrated that scattering is negligible in relation to absorption [15], thus Bouguer's law can be reduced to the following equation:

$$
\frac{i_{\lambda}(x, L y, z)}{i_{\lambda}(x, 0, z)}=e^{-\int_{0}^{L y} a_{\lambda}(x, y, z) d y}
$$

The two-dimensional assumption then leads to directly infer the local absorption coefficient $a_{\lambda}(x, z)$ from the measurement of $A_{\lambda}$, called here extinction factor:

$$
a_{\lambda}(x, z)=-\frac{1}{L y} A_{\lambda}, \quad A_{\lambda}=-\log \left(\frac{i_{\lambda}(x, L y, z)}{i_{\lambda}(x, 0, z)}\right)
$$

Measuring extinction $A_{\lambda}$ could lead to an error because LEDs induce emission along their path. However, as mentioned by Siegel and Howell [16], the error does not exceed 1\% so long $\lambda T<$ $3120 \mu \mathrm{m} . K$. At the LED wavelength of $530 \mathrm{~nm}$, this would lead to errors in the range of $1 \%$ up to a temperature of $5885 \mathrm{~K}$, which is obviously too high for a diffusion flame. Therefore, this work does not account for the induced emission process.

Chopping the LEDs source allows the subtraction of an image with no backlight (flame emission) from a backlight one (flame emission + light) and a correct extinction measurement can be made. For particles of small optical dimension, the extinction factor $A_{\lambda}$ and the formula obtained from Mie theory [17] at a single wavelength $\lambda$ should be sufficient to establish a relationship between soot volume fraction $f_{\text {soot }}$, the dimensionless absorption constant $K_{e}$ and path of length:

$$
f_{\text {soot }}(x, z)=\frac{-A_{\lambda}(x, z) \lambda}{K_{e}\left(n_{\lambda}, \kappa_{\lambda}\right) L y}
$$

where $n_{\lambda}$ and $\kappa_{\lambda}$ are respectively the real and the imaginary parts of the refractive index at the considered wavelength. 


\section{Results and discussion}

The origin $(0,0,0)$ is located at the crossing of the leading edge of the PMMA plate ( $c f$ Fig. 2$)$ and the $(x, z)$ plane of symmetry. In this way, the PMMA plate was defined as $\{0 \leq x \leq 60 \mathrm{~mm} ;-30 \mathrm{~mm} \leq y \leq 30 \mathrm{~mm} ; \mathrm{z}=0\}$. Experimental curves showed that the data is distributed in a symmetrical way, so only one side of the measurements in a $(y, z)$ plane will be presented.

Figure 4 displays an instantaneous grey scale frame of from the CCD camera used for the extinction measurements. It can be observed that the particle layer can be found under the region of highest flame emission and increases in thickness even beyond the burner trailing edge. Observation of the instantaneous images shows that soot formation is initially favored but oxidation acquires a more significant role as $x$ increases. Eventually, soot concentrations will reach a critical value that will lead to flame extinction via radiative losses, at this point soot oxidation is thus hampered. A more rapid increase in soot concentration follows.

This process can be observed more clearly in Figure 5 where extinction factor measurements $A_{\lambda}$ are plotted against $z$ coordinate. Fig. 5 presents measurements of the emission and extinction factor $A_{\lambda}$ at different $x$ streamwise coordinate values versus $z$ coordinate for $U_{\infty}=200 \mathrm{~mm} \cdot \mathrm{s}^{-1}$. Initially the peak extinction factor slowly increases with the distance downstream (see $x=65 \mathrm{~mm}$ and $x=75$ $\mathrm{mm}$ ). At approximately $x=75 \mathrm{~mm}$ the flame quenches and this is accompanied by a sudden increase in the extinction coefficient. The peak continues to increase up to $x=85 \mathrm{~mm}$. Finally, at $85 \mathrm{~mm}$ the magnitude is maximal and then it is stabilized until $x=95 \mathrm{~mm}$. Throughout the length of the burner the shape of the extinction factor curve evolves, but for $85 \mathrm{~mm}<x<95 \mathrm{~mm}$ the curves show a consistent extinction factor characteristics in peak value and width (z direction). The term "width" is given to the width of the curves in Figure five at half the peak value of $A_{\lambda}$.

For a given curve, $z_{\max }$ defines the location of the extinction factor maximum. For $z>z_{\max }$, the curve can be seen to keep analogous shapes. Here, the rays can be assumed to pass through the flame unaffected by three-dimensional effects. For $z<z_{\max }$, where flame curves towards the burner surface 
the extinction factor will be affected by three dimensional effects and a correction will be necessary. A correction methodology can be found in the work of Legros [18] but will not be discussed here.

Figure 6 displays the extinction factor and flame emission in grey scale versus $z$ coordinate, for different oxidizer velocities at $x=65 \mathrm{~mm}$. The emission measurement is obtained from images where the LEDs are off and the flame is present. The emission was plotted between 0 to 255 gray levels, where 255 representing maximal emission. Principally, the figure shows that the extinction factor and emission augment with the oxidizer velocities. Detailed observation of this graph shows that as the extinction factor increases, the emission and extinction peaks separate as the velocity increases. It seems, therefore, that an increase in oxidizer flow results both in an increase in oxidation and in soot formation.

\section{Conclusions and perspective}

This study has provided a methodology to estimate the extinction factor at different cross-sections for microgravity laminar diffusion flames established over a non-axisymetric burner. Experimental data for PMMA solid fuel were presented to illustrate this method.

The extinction factor can then be used directly to compute the soot volume fraction (see Eq. 4). Under such assumptions, Dazell and Saforim [17] showed that a single measurement can be placed into the $a_{\lambda}$ curve and should be sufficient to fit the experimental curve. Thus these measurements provide a means to obtain soot concentrations for non-axisymetric laminar diffusion flames in micro-gravity. Extrapolation of the extinction factor from the two-dimensional study is possible, but if the focus is on estimating the soot concentration, a correction should be made in the inner region enveloped by the flame. This correction cannot be achieved by analytical solutions, mainly because the flame-induced thermal expansion results in three dimensional flow patterns that cannot be described using analytical techniques. 


\section{Acknowledgements}

The authors gratefully acknowledge the team of ZARM Drop tower for your contribution in the integration of experimental. We also acknowledge helpful discussion provided by Dr. Irmin Meyer of EADS. Finally, this work was funded by ESA. 


\section{References}

[1] Olson, S.L. and T'ien, J.S.: Buoyant Low-Stretch Diffusion Flames beneath Cylindrical PMMA Samples, Combust. Flame, 121 (3), 439 (2000).

[2] Megaridis, C.M., Konsur, B., and Griffin, D.W., Proc. Combust. Inst., 26, 1291 (1996).

[3] Fernandez-Pello, A.C., Walther, D.C., Cordova, J.L., Steinhaus, T., Quintiere, J.G., Torero,J.L., and Ross, H.: Test Method for Ranking Materials Flammability in Reduced Gravity, Space Forum, 6, 237 (2000).

[4] Torero, J.L., Vietoris, T., Legros, G., and Joulain, P.: Estimation of a Total Mass Transfer Number from the Stand-Off Distance of a Spreading Flame, Combust. Sci. Technol., 174 (11-12), 187 (2002).

[5] Law, C. K., and Faeth, G. M., Prog. Energy Combust. Sci. 20: 65 (1994).

[6] Sunderland, P.B., Mortazavi, S., Faeth, G.M., and Urban, D.L.: Laminar Smoke-Point of Nonbuoyant Jet Diffusion Flames, Combust. Flame, 96, 97 (1994).

[7] Urban, D.L., Griffin, D.W., and Gard, M.Y.: Smoke-Point Properties of Non-Buoyant Round Laminar Jet Diffusion Flames, Proc. Combust. Inst., 28, 1965 (2000).

[8] Konsur, B., Megaridis, C.M., and Griffin, D.W.: Fuel Preheat Effects on Soot-Field Structure in Laminar Gas Jet Diffusion Flames Burning in 0-g and 1-g, Combust. Flame, 116 (3), 334 (1999).

[9] Konsur, B., Megaridis, C.M., and Griffin, D.W.: Soot Aerosol Properties in Laminar SootEmitting Microgravity Nonpremixed Flames, Combust. Flame, 118 (4), 509 (1999).

[10] Mortazavi, S., Sunderland, P.B., Jurng, J., Köylü, Ü.Ö., and Faeth, G.M.: Structure of SootContaining Laminar Jet Diffusion Flames, AIAA paper, 93-0708 (1993).

[11] Vietoris, T., Ellzey, J.L., Joulain, P., Mehta, S.N., and Torero, J.L. (2000) Laminar Diffusion Flame in Micro-Gravity: the Results of the Mini-Texus 6 Sounding Rocket Experiment, Proc. Combust. Inst., 28, 2883. 
[12] Brahmi, L., Vietoris, T., Joulain, P., and Torero, J.L.: Détermination par caméra infrarouge des distributions de température sur l'enveloppe d'une flamme de diffusion établie sur un brûleur plat en microgravité, Entropie, 215, 69 (1998).

[13] Rouvreau, S., Joulain, P., Wang, H.Y., Cordeiro, P., and Torero, J.L.: Numerical Evaluation of Boundary Layer Assumptions Used for the Prediction of the Stand-Off Distance of a Laminar Diffusion Flame, Proc. Combust. Inst., 29, 2527 (2002).

[14] ZARM FABmbH : ZARM Drop Tower Bremen, User Manual, (2003).

[15] Sivathanu, Y. R., and Faeth, G. M.: Soot Volume Fractions in the Overfire Region of Turbulent Diffusion Flames, Combust. Flame 81:150 (1990).

[16] Siegel, R., and Howell, J.R.: Thermal Radiation Heat Transfer second edition, Hemisphere Publishing Corporation, (1981).

[17] Dalzell, W.H. and Sarofim, A.F.: Optical Constants of Soot and their Applications to Heat Flux Calculations, J. Heat Transfer, 91, 100 (1969).

[18] Legros, G., Joulain P., Vantelon, J.P., Breillat, C., and Torero, J.L. : Estimation of a Soot Layer Optical Thickness Produced by a Diffusion Flame Established in Microgravity, Proc. Third Mediterranean Combustion Symposium, 557 - 568 (2003). 


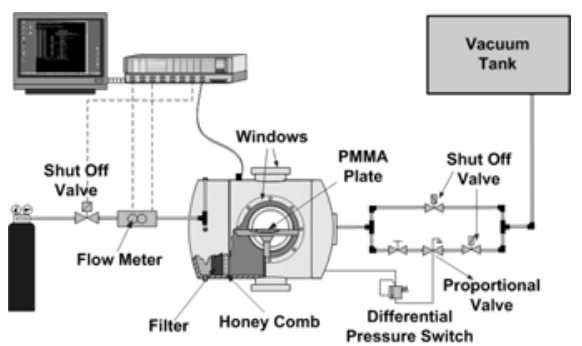

Fig. 1 Schematic of the combustion chamber

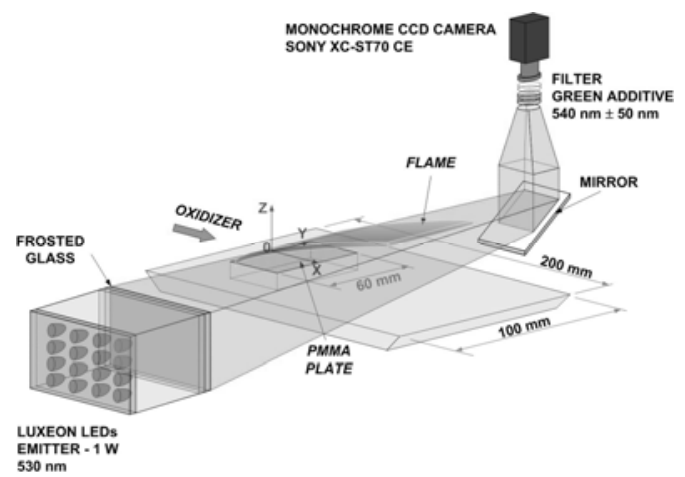

Fig. 2 Experimental optical system

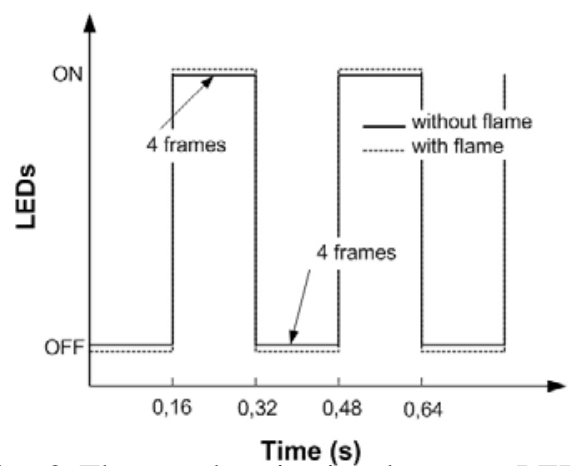

Fig. 3 The synchronization between LEDs and camera during a typical experimental run.

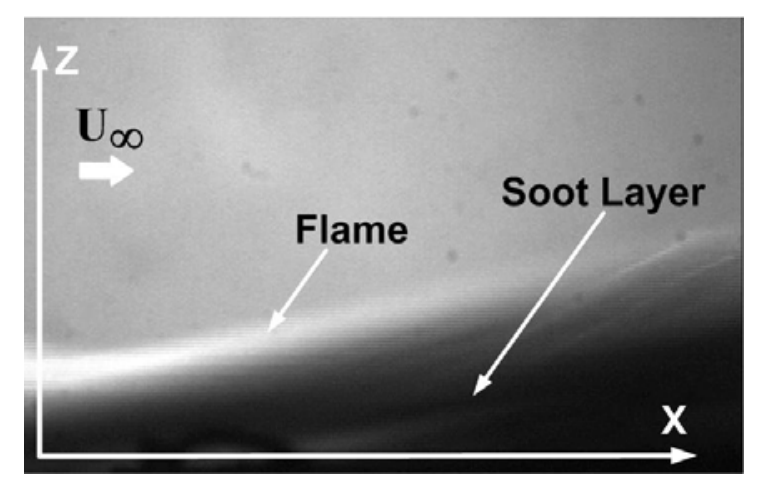

Fig. 4 Backlighting picture of a flame under microgravity conditions. This case correspond to $\mathrm{U}_{\infty}=250$ $m m \cdot s^{-1}$ and $\mathrm{Y}_{\mathrm{O}, \infty}=0,38$

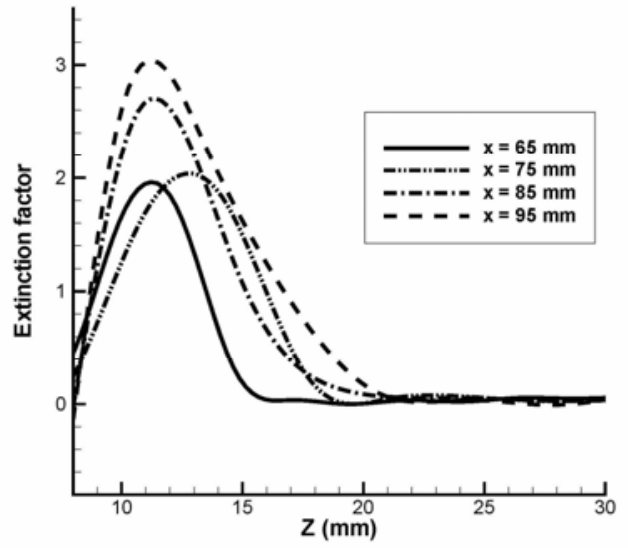

Fig. 5 Cross-sections at different $x$ streamwise coordinate values, plotting extinction factor versus $z$ coordinate, from gray scale picture of the LEDs extinction through the flame (cf Fig. 4).

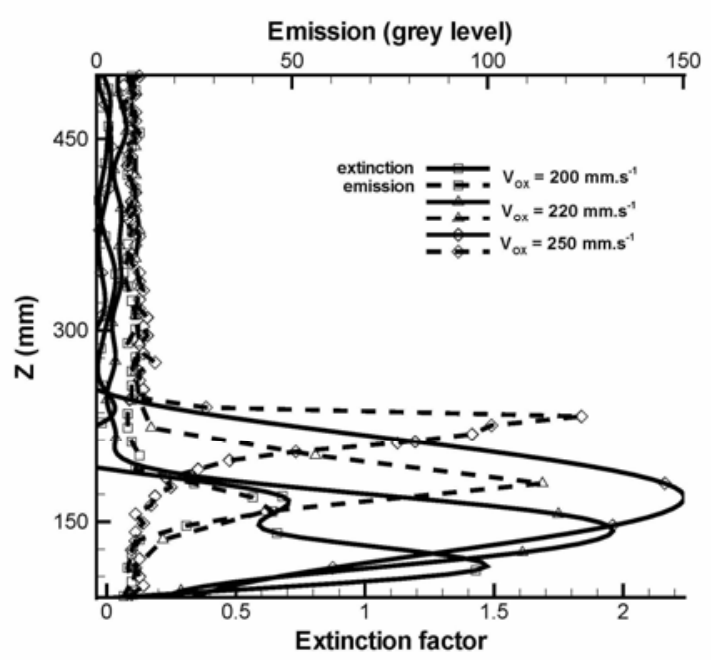

Fig. 6 Cross-sections at $x=65 \mathrm{~mm}$, plotting extinction factor (solid lines) and emission (dashed line) versus $z$ coordinate for different oxidizer velocities and a $\mathrm{Y}_{\mathrm{O} 2, \infty}=$ 0,38 . 